\title{
DE MORALIDAD Y ETICIDAD. DOS DIMENSIONES PARA LA BIOÉTICA
}

\author{
Eduardo Díaz Amado*
}

\begin{abstract}
Resumen: La Bioética tiene como reto argumentar en un contexto de multiplicidad de voces éticas. El mundo de hoy está constituido por «amigos» y «extraños» morales, al decir de T. Engelhardt, lo que torna difícil la búsqueda de autoridad moral con base en un mismo contenido. La Bioética debe proponer interpretaciones y noemas para la acción en diversos escenarios: justicia sanitaria, investigación clínica, biodiversidad, genética, entre otros.

Siendo éste el reto de la Bioética, resulta útil distinguir, según ha expuesto J. Habermas, lo pragmático, lo ético y lo moral como diferentes usos de la Razón Práctica. Se trata de un lenguaje que pertenece a la tradición kantiana, de la cual hoy todos formamos parte cuando se hace filosofía sobre lo moral. A pesar de que T. Engelhardt no cree en la Teoría de la Acción Comunicativa de Habermas como solución al problema moral contemporáneo, el lenguaje de este último puede ser clave para el ámbito de la Bioética.
\end{abstract}

Palabras clave: Amigos morales, extraños morales, razón práctica, pragmático, ético, moral

\section{MORALITY AND ETHICS. TWO DIMENSIONS FOR BIOETHICS}

\begin{abstract}
Bioethics, in providing a stage for interdisciplinary discussion has as its challenge to argue in a context in which there is a multiplicity of ethical voices. The world today, consists of moral "relatives" and moral "strangers", as said by T Engelhardt; the difficulty lies in the return to the search for a moral authority with a communal base content. Bioethics must put forth interpretations and appoint norms for the working in diverse scenarios as justice in health, clinical research, biodiversity and genetics amongst others.

This challenge for bioethics results in a useful distinction, following that, which has been expressed by J.Habermas: the pragmatic, the ethical and moral used as different applications of Practical Reason. Furthermore to speak of a language which belongs to the Kantian tradition, of which today we are all part whenever philosophy concerns that which is moral. Despite the fact that T Engelhardt does not believe Habermas's Theory of Communicative Action to be a solution to the contemporary moral problem, the language of this work may be vital for the field of Bioethics.
\end{abstract}

Keywords: Moral friends, moral strangers, practical reason, pragmatic, ethics, moral

\section{SOBRE A MORALIDADE E ETICIDADE. DUAS DIMENSÕES PARA A BIOÉTICA}

Resumo: A Bioética tem como desafio argumentar num contexto de multiplicidade de vozes éticas. O mundo hoje está constituído por "amigos" e "estranhos" morais, no dizer de T. Engelhardt, o que torna difícil a busca de autoridade moral tendo como base um único conteúdo. A Bioética deve propor interpretações e normas para ação em diversos cenários: justiça sanitária, investigação clínica, biodiversidade, genética, entre outros.

Sendo este o desafio da Bioética, parece útil distinguir, como já exposto por J. Habermas, o pragmático, o ético e o moral como diferentes aportes da Razão Prática. Trata-se de linguagem que tem origem na tradição kantiana, da qual todos fazemos parte quando se refere a filosofia sobre moral.Mesmo considerando que T. Engelhardt não acredita na teoria da Ação Comunicativa de Habermas como instrumento para a solução do problema moral contemporâneo, a linguagem desse último pensador pode ser decisiva para a Bioética.

Palavras chave: Amigos morais, estranhos morais, razão prática, pragmático, ético, moral

\footnotetext{
* M.D. Investigador titular del Instituto de Bioética, Universidad Javeriana, Colombia Correspondencia: eduardo.diaz@javeriana.edu.co
} 


\section{Introducción}

Como contribución a la discusión que se viene dando en el terreno de la Bioética en un contexto de Posmodernidad y Multiculturalidad, en el que, sin embargo, se hacen necesarios juicios que orienten la acción, sobre todo en lo referente a lo que la ciencia y la técnica proponen como caminos que deben tomarse tanto para el presente como para el futuro de la humanidad, considero relevante traer a colación los conceptos de moralidad y eticidad explicados por J. Habermas. No se trata de decir finalmente qué es Ética y qué es Moral, pero más allá de las discusiones académicas entre filósofos, existe una necesidad sentida en el ámbito de las discusiones públicas que reclama orientaciones para que el no experto la sociedad completa- pueda moverse con seguridad en medio de la pluralidad; que lo guíe sin complejidades, sin presiones. Tal vez quienes sólo aceptan un contexto de "definiciones clásicas" consideren como error un lenguaje aparentemente distinto, pero habría que decir que hoy, como nunca, en el ideal de una sociedad verdaderamente democrática, lo importante es lograr un acuerdo que cobije sin discriminaciones a cada uno de sus miembros, para lo cual todos deberán participar en la búsqueda de ese acuerdo. A tal fin se considera que contribuye el plantear nuevas maneras de entender la Ética y la Moral.

El problema señalado por $\mathrm{T}$. Engelhardt, uno de los teóricos más importantes de la Bioética, acerca de que lo que caracteriza la discusión moral contemporánea, en especial la que se traza en el ámbito de la salud y la asistencia sanitaria, es que "continuamos buscando intensamente una bioética dotada de contenido secular, concretamente, una explicación secular dotada de contenido de la justicia y de la relación adecuada entre paciente y médico" $(1, p .31)$. Esto pone de manifiesto en dónde hemos quedado luego del derrumbamiento de los metarrelatos(2). No cabe duda que hay una nostalgia del punto de vista igual para todos. La creencia en un solo Dios, que antaño dio contenido al discurso moral, hoy es, para pesar de muchos y alegría de otros, un dato del pasado. Sin un punto de vista que asuma el mismo talante de esa creencia no parece ser posible dar solución a la controversia sobre cuestiones relativas a lo que debe ser considerado "bueno para todos".

Ante este panorama se puede pensar que la solución sería buscar maneras que nos lleven nuevamente a compartir un mismo punto de vista sobre lo que es bueno extraído de una fe nacida en el pasado. Sin duda ésta sería una especie de solución porque al compartir una misma creencia, cabría esperar cierta armonía en el abordaje de los dilemas en el terreno de lo moral ${ }^{1}$. Que esto suceda es el sueño de quienes consideran que su propia fe es la verdadera y, su obligación, hacerlo ver así a todos los demás. Pero mientras esto sucede, si es que sucede, tenemos de todos modos que buscar un fundamento a la pregunta qué debemos hacer en el plano de la sociedad como un todo y, a veces, incluso en el plano de toda la humanidad, como sucede ahora en lo concerniente a la manipulación genética. Igual, en tanto individuos, pues tenemos que respondernos permanentemente la misma pregunta en singular.

La otra opción puede ser intentar "reconstruir", sobre esta colcha de retazos que es el mundo moral contemporáneo(3), nuevas maneras de acceder a lo moral. Como la homogeneidad de creencia de hecho no existe hoy, podemos echar mano todavía de las herramientas que, a pesar de todo, siguen vigentes desde

\footnotetext{
Aclaro que cuando hablo de "lo moral" me estoy refiriendo a
} un ámbito que incluye Ética y Moral. 
que el hombre, por lo menos en Occidente, decidió que era posible construir la Moral y la Ética a partir de una fundamentación que no fuera metafísica, en los albores de la era de la autonomía. En otros términos, al dar también por aceptado en este artículo que vivimos en una época postmetafísica -lo que no quiere decir que la Metafísica haya desaparecido sino que ahora ocupa un lugar distinto en nuestra sociedad- y que, sumado al cambio que produjo en nuestra comprensión del mundo el llamado "giro lingüístico"(4), nos queda entonces el silencio frente a cuestiones relativas a "esencias", recordando lo que planteaba Wittgenstein en su famosa conferencia sobre Ética(5), y dialogar para ponernos de acuerdo. Por esto será importante que logremos ver la diferencia entre lo ético y lo moral.

De este modo propondré en el presente artículo los conceptos habermasianos de Ética y Moral como de gran ayuda en la discusión bioética, pues, por un lado, ellos pueden ser "explicados" y "justificados" a través del diálogo mismo y, por el otro, haciendo que la exigencia de una sola fe no sea suficiente, convirtiendo en necesario el argumentar, ya que los agentes morales ${ }^{2}$ están en la capacidad y la obligación de hacerlo a fin de serlo efectivamente.

\section{Configuración de nuestro actual mundo moral}

Para Engelhardt es característica de nuestro actual mundo moral lo que él llama pluralidad de visiones morales, en una sociedad que se ha autodefinido como multicultural. La diversidad cultural está relacionada con una aparente diversidad moral, algo que para muchos implica de manera preocupante la acep-

${ }^{2}$ Engelhardt define a los agentes morales, es decir, las únicas entidades con capacidad de discurso moral, como las que poseen tres características: AUTORREFLEXIÓN, RACIONALIDAD Y SENTIDO MORAL $(1, p .155)$ Compartimos esta definición. tación de que "todo está permitido". Ya Nietszche nos anunció que "Dios ha muerto", frase trajinada en muchos sentidos, pero que debe ser entendida en el sentido de que el hombre contemporáneo, y desde hace ya por lo menos dos siglos, no parece tener puntos fijos y confiables sobre los cuales apoyarse para decidir acerca de cómo actuar. El panorama de la Bioética actual es entonces verse enfrentada "a una situación que se caracteriza por un considerable escepticismo, por la pérdida de la fe y de convicciones persistentes, por la pluralidad de visiones morales y por crecientes cambios de política pública" $(1, p .34)$.

Si el mundo moral contemporáneo está constituido a modo de una gran colcha de retazos es porque conviven entre nosotros múltiples ethos recibidos del pasado. Sin embargo, nuestro patrimonio actual en lo moral no consiste solamente en unas eticidades que hayamos heredado, es también el producto de elaborarlas en nuestro propio contexto histórico y cultural, nuestro presente. La totalidad es más que la suma de sus partes. El no comprender esto lleva a que en algunos sectores de la sociedad, por ejemplo en el seno de una creencia o una fe religiosa específica, los individuos pretendan asumir su propio ethos como el todo moral. Es el resultado de no darse cuenta de que el punto de vista moral de la sociedad está hoy más allá de esa sola eticidad. Pareciera que tales posiciones niegan de plano nuevas elaboraciones, entienden el mundo moral como inmutable, mientras pueden aceptar sin ambages que esa sociedad y la cultura no lo son, como si aquél y éstos fueran independientes entre sí. En esta situación cualquier punto de vista que incluya nuevas comprensiones sobre lo moral es tildado de inaceptable, en cuanto no se sujete absolutamente al punto de vista elaborado en algún punto del pasado. Pero lo problemático no es tanto el desacuerdo teórico como la pendiente que suele aparecer con facilidad, y por la cual determinado sector -social, político o religioso-, emprende acciones de represión o coerción, haciendo uso de la fuerza sin justifi- 
cación por querer imponer la propia concepción de lo moral. La rigidez en cualquier aspecto de la vida, en este caso en el terreno de lo moral, es el pathos.

Por esto la capacidad de los individuos para comprender esta circunstancia permitirá en mayor o menor medida la construcción de lo que Engelhardt llama sociedades pluralistas seculares pacíficas, que él define como aquellas sociedades que "aceptan en su seno diversos puntos de vista morales, al tiempo que gozan de libertad para opinar en materias morales sin miedo a la represión" $(1, p .35)$. Esto significa que sólo quedan posibilidades de conquista a través de vías tales como el arte, el ejemplo de vida y, claro está, también de razones que convenzan a quienes les parezca que su propio punto de vista de lo Bueno debería ser implementado en la sociedad en general. No creo que haga falta aquí mostrar el por qué es hoy una tarea de la humanidad intentar construir una sociedad pacífica, que respete la diferencia y que, a la vez, sea secular en el sentido de obviar el mandato de una religión determinada para proveer autoridad moral pues, por ahora, una conversión general es imposible. Sin embargo, el asunto de la fe podrá seguir siendo discutido públicamente, pero tratado como un asunto privado.

Cuando se comparte una visión moral particular, los individuos constituyen comunidades que se caracterizan por tener referentes comunes acerca de lo que hay que hacer o decidir correctamente. Saben qué cosas son loables y cuáles producen sentimientos de culpa, de indignación o de vergüenza, en palabras de E. Tugenhadt(6). De otro lado, Taylor ha señalado que en tanto compartimos la pertenencia a una comunidad o cultura dadas, estamos unidos unos a otros a través de discriminaciones compartidas acerca de lo que es bueno o errado, lo que es mejor o peor. Tales discriminaciones no son válidas como producto del propio deseo, inclinación o escogencia del individuo que pertenece a esa comunidad. Son pro- ducto de lo que él denomina valoraciones fuertes (strong evaluation)( $7, p .4$ ) que constituyen una especie de modelo común, supraindividual, que deben seguirse en esa comunidad, esto es, en el ámbito de un ethos, para lograr el discernimiento en el terreno de lo moral.

En el contexto de la Posmodernidad, es decir, de la crisis de los discursos universales, que en un momento de la Historia pudieron hacer posible una comunidad moralmente homogénea ${ }^{3}$, la idea que a muchos les nace es que deberíamos buscar "la moral" perdida que nos vinculaba "fuertemente" a todos. Una idea persistente es que sólo una moral con contenido tiene la fuerza necesaria para que los individuos "hagan lo que deben hacer". Si hubo alguna vez la posesión compartida homogéneamente por todos de cierto contenido de la Moral, hoy ya no es así. Por esto debemos reconocer con Engelhardt que hoy, "cuando los individuos intentan resolver controversias no escuchan a Dios de la misma manera y no encuentran argumentos racionales bien fundados para resolver sus controversias morales, [...] sólo les queda el recurso de ponerse de acuerdo pacíficamente sobre cómo y hasta qué punto colaborar. [...] sólo puede derivarse [autoridad moral] de los individuos"4 $(1, p .21)$.

De lo anterior podemos extraer dos cuestiones: primero, dado que el contenido de una moral establecida no es compartido por todos, para el ámbito de las cuestiones públicas sólo contamos con la vía formal, procedimental, para resolver los dilemas morales que se presentan en el seno de nuestra sociedad plural y, segundo, que toca a los individuos resolver entre ellos como personas o

\footnotetext{
${ }^{3}$ Un ejemplo de un periodo de la Historia en el que podemos ver una moral homogénea es el Occidente Cristiano de la Edad Media.

${ }^{4}$ Engelhardt entiende aquí individuos en tanto agentes morales (ver nota 2) Y específicamente está refiriéndose a la voluntad de esos individuos, expresada en el otorgar consentimiento. Más adelante veremos cómo voluntad no puede ser sino Razón Práctica.
} 
agentes morales tales dilemas. Esto lo pueden lograr en tanto se den cuenta que las afirmaciones deducidas de un particular contenido moral deben ser "convertidas" en argumentos para que puedan ser captados por quienes no aceptan o entienden dicho contenido. Las convicciones con contenido sólo funcionan sin necesidad de justificación al interior de un mundo moral privado que, al pretender funcionar igual en el ámbito general plural, sólo pueden lograrlo incurriendo en heteronomía, que no es propiamente el ideal que perseguimos hoy en el terreno de lo moral. La vía de la argumentación deberá ser escogida porque puede ser entendida como una especie de "esperanto moral" que, al igual que en el mundo de los lenguajes naturales, pocos lo utilizan efectivamente pero que está diseñada para ser aprendida y entendida fácilmente por todos a efectos de hacer posible la comunicación. Ya MacIntyre había hecho énfasis en este aspecto de los discursos morales comprometidos con un contenido, al señalar la intraducibilidad e inconmensurabilidad de éstos cuando se intenta que uno de ellos sea "hablado" con los términos de un discurso rival(8). Por esto hoy no podemos eludir la cuestión de justificar públicamente mediante la argumentación cualquier idea de lo Bueno que pretenda hacerse extensible a todos los miembros de la sociedad.

Así, en el ámbito de las discusiones morales ocurre hoy que, o estamos frente a amigos morales, o frente a extraños morales ${ }^{5}$. Según Engelhardt, los primeros comparten una misma visión moral, y los segundos, poseen

\footnotetext{
5 Engelhardt afirma que hay "que contrastar la moralidad dotada de contenido con la moralidad de procedimiento en la que las persona imprimen a sus esfuerzos colectivos la autoridad moral de su consentimiento, pero no encuentran otras señales morales que les sirvan de guía que todos puedan compartir. [...] 'Amigos morales' son los que comparten una moralidad dotada de contenido y pueden así resolver sus disputas morales mediante argumentos racionales bien fundados o apelando a una autoridad moral reconocida por todos, cuya jurisdicción todos aceptan que procede de una fuente distinta al mutuo acuerdo. Los 'extraños morales' tienen que resolver sus desacuerdos morales por mutuo acuerdo, ya que no comparten una visión moral que les permita encontrar soluciones dotadas de contenido en las controversias morales." $(1, p$. 455)
}

visiones morales diferentes entre sí, muchas veces incompatibles. El problema más complicado estará en intentar resolver problemas morales apelando a un contenido entre extraños morales y no tanto entre amigos morales. Este es el intento de las diversas propuestas o modelos actuales nacidos en el ámbito del Derecho, la Filosofía o la Política, también en el de la Bioética, que apelan a determinada concepción o modelo ${ }^{6}$ sin tener que acudir a algún contenido. Pero, según Engelhardt, tienen el problema de que parten ya de una visión moral particular que, por supuesto, no es compartida por todos, pues "toda elección moral concreta presupone un sentido moral particular". Claro, porque para que exista ese "sentido moral particular" compartido por todos hace falta un lenguaje común, y éste será posible en tanto cada cual tome distancia de la propia eticidad que sólo le provee de un lenguaje privado. Todos estos lenguajes privados constituyen lo que Engelhardt llama pluralidad de visiones morales.

Para alguien que pertenece a una comunidad moral dotada de contenido, que no toma cierta distancia de su propia eticidad, porque no quiere o no sabe cómo, es "intuitivamente" incorrecto o condenable lo que él interpreta como connivencia con una mera formalidad, con una especie de vacío de sentido. Sin embargo, de lo que podría acusarse a este individuo es de molestarse, no por una falta de contenido -él ya lo tiene, recordemos lo dicho por Taylor; todos vivimos en un ethos-, sino porque se da cuenta que no todo el mundo comparte con él ese contenido, es decir, por una especie de "egoísmo ético". Hay un costo que debemos pagar en aras de una sociedad pacífica, el de reconocer que no puede ni tiene por qué haber una eticidad exclusi-

\footnotetext{
"Piénsese, para el caso de la Bioética, en el "principialismo" norteamericano.
} 
va, reconociendo que cada persona debe ser respetada en sus convicciones y en sus creencias como en su propio desarrollo; $;^{7}$ así como rechazando la crueldad, la humillación y la tortura $^{8}$, tanto más si se está buscando por esta vía imponer determinado contenido moral. El uso y la forma de la fuerza deberá ser sometido a justificación pública en términos racionales al interior de la comunidad plural -el Derecho, por ejemplo-, si se pretende legitimidad moral en una acción que recurra a ella. Por esto Engelhardt termina afirmando que "plantear una cuestión ética es buscar un fundamento distinto a la fuerza para resolver una controversia"(1, p.91).

\section{Una explicación de lo pragmático, lo ético y lo moral}

Kant llamó Razón Práctica (RPr) a ese aspecto o cualidad de los seres humanos con capacidad de razonar que logra determinar sus decisiones y actos en cada situación. Es decir, en esos seres la respuesta a la inevitable pregunta del día a día de esta vida ¿qué debo hacer? tiene condición de posibilidad de ser formulada y respondida. Kant explica cómo los cursos de acción elegidos dependen de una estrecha relación entre conocimiento y volun$\operatorname{tad}(9)$. Son estos dos componentes entrelazados los que distinguen la RPr de la Razón Pura, cuya característica es posibilitarnos conocimientos sin depender del mundo de la experiencia, por ejemplo, el conocimiento matemático. En la Razón Pura no hay voluntad. Por esto cuando se trata de actuar o de decidir no basta sólo saber o conocer en general, hace falta la voluntad, que en tanto se realiza según diversos modos de fundamentación desde la Ra-

\footnotetext{
${ }^{7}$ En la Constitución Política de Colombia, que nació con un talante secular y plural en 1991, se plasmó como un derecho fundamental "el libre desarrollo de la personalidad".

${ }^{8}$ Los Derechos Humanos en su génesis y evolución son una prueba de esto.
}

zón, se constituye en RPr. De este modo entendida, "la voluntad no es otra cosa que razón práctica” $(9, p .155)$. Esta caracterización de la RPr lleva a que una discusión sobre lo moral no pueda ignorarla sino más bien deba buscar discernir su funcionamiento.

Según explica Habermas, es posible un uso distinto de la RPr "bajo los aspectos de lo adecuado a fines, de lo bueno y de lo justo" $(10, p .7)$. Esta circunstancia señala que, frente a posibilidades de acción o de decisión, la pregunta sobre qué hacer obtiene una respuesta distinta según las determinaciones que de hecho la configuran, lo que puede traducirse a que "en todos los casos se trata de la fundamentación $n^{9}$ de decisiones entre posibilidades de acción alternativas"(10, p.14).

Hay situaciones en las que nuestra decisión estará sujeta a un fin que aparece condicionando nuestra acción. Se trata de situaciones en las que nos vemos obligados a actuar tenemos que- si queremos obtener un determinado fin. En estos casos lo que uno "debe" hacer está condicionado por lo que uno quiere, en tanto se trate de elegir racionalmente los medios ante determinados fines o de elegir los fines mismos. ${ }^{10}$ La cuestión es, entonces, una cuestión pragmática. En estos casos "nuestra voluntad está ya fácticamente determinada por deseos y valores" $(10, p .8)$. La pregunta pragmática típica tiene que ver con cuál será la mejor estrategia con miras a la consecución de un fin.

Sin embargo, cuando los mismos deseos y valores se tornan problemáticos, es decir, cuando son ellos mismos el tema de la pregunta qué debo hacer, nos adentramos en un

\footnotetext{
${ }^{9}$ El uso de cursiva es mío.

${ }^{10}$ Por ejemplo cuando se nos daña la bicicleta, lo que se haga estará encaminado a la reparación -que tiene que hacerse- lo mejor y más rápidamente posible.
} 
terreno ubicado más allá de la adecuación de los medios ante unos fines dados, que es el de la Ética. Ahora se trata de la pregunta acerca de la manera cómo uno debería llevar la propia vida, que en el fondo es la búsqueda de lo que significa una vida buena. En tal caso habrá que preguntarse qué es lo Bueno, y lo que ello sea tendrá importancia en primera instancia sólo para quien se ha cuestionado sobre la propia vida. Por esto la pregunta ética típica es qué es lo bueno para mí en cuanto apunta a decisiones que conciernen a la evaluación de la propia vida como "una vida buena". Sólo quien se pregunta acerca de lo Bueno, para fundamentar sobre tal concepto la propia vida, puede arribar a la Ética. Este es el reto para los que aún viven irreflexivamente bajo la égida de lo que ha sido declarado Bueno por otros, es decir, los que aún no salen de la minoría de edad para valerse por sí mismos en dar un sentido y orientación a la propia vida, aceptando la invitación de Kant que lleva a la autonomía.

Pero, ¿por dónde comenzar para llegar a saber qué sería bueno para mí? Habermas afirma que "quien en decisiones importantes para la vida no sabe lo que quiere preguntará al final quién es él y quién desearía ser" $(10, p .10)$. La pregunta ética qué es lo bueno para mí se responde tanto más fácil cuanto más claro tengamos quiénes somos y quiénes desearíamos llegar a ser. Esto apunta a que para ser hombres que actúan éticamente estamos obligados a conocernos a nosotros mismos y a definirnos, lo que implica no sólo una mirada histórico-vital (quién soy en el más amplio sentido, cuál es mi ethos, cuál mi cultura, todo aquello que ha contribuido a que sea el que soy ahora, etc.) sino también una mirada que, por mediación del modelo que decido seguir, la mirada normativa del yo-ideal, también me define. Es claro, entonces, que para movernos en el terreno de la Ética debemos optar en primer lugar, y por principio, por la autocomprensión, a partir de la cual la RPr tendrá cómo elegir, no sólo por lo estratégico y lo adecuado a fines, sino también por lo Bueno.

Ahora bien, "la pregunta ¿qué debo hacer? transforma una vez más su sentido tan pronto como mis actos tocan los intereses de los otros y conducen a conflictos que deben ser regulados imparcialmente ${ }^{11}$, esto es, bajo puntos de vista morales" $(10, p .11)$. En esto consiste ahora el adentrarnos en la Moral, en tratar de resolver conflictos intersubjetivamente de manera imparcial.

Los individuos se ven permanentemente enfrentados no sólo a decidir cómo llevar a cabo un plan de vida con sentido para sí mismos; en palabras de Habermas un proyecto de vida normativamente sustancial, sino también a decidir junto a las preferencias de otros, a entrar en relación con las diferentes concepciones de lo Bueno que tienen los otros. Cuando se trata de saber qué debo hacer, entendido como lo mismo que debe hacer otro, donde "otro" significa que están presentes otras concepciones de lo Bueno, entramos al terreno del "todos deberían", que es el terreno de la Moral. Como es fácil darse cuenta de que el punto de vista individual, a través del cual llegamos a saber lo que es bueno para sí, no necesariamente coincide con lo que es bueno para otros, lo que podríamos asimilar aquí a un concepto del tipo "lo Bueno para todos" no significa otra cosa que lo justo, e implica de este modo una mirada distinta que ha tomado distancia de la egocéntrica mirada y que tan solo alcanza para ver lo que es bueno para sí: "sin un cambio radical de la perspectiva y de la orientación no se puede percibir el conflicto interpersonal de los involucrados como un problema moral"'(10, p.12).

\footnotetext{
${ }^{11}$ El uso de cursiva es mío.
} 
Por otro lado, la Moral sólo es posible cuando la actuación no es producto de una contradicción, es decir, cuando voluntad y conocimiento moral coinciden, pues ya sabemos que la voluntad no puede más que realizarse como RPr, en este caso bajo el uso moral. Cuando ocurre esta contradicción aparecen sentimientos de culpa, que señalan una escisión entre voluntad y Razón(10, p.21).

Kant propuso el uso del imperativo categórico precisamente para no entrar en contradicciones y saber si una acción es moral: “obra sólo según la máxima a través de la cual puedas querer al mismo tiempo que se convierta en una ley universal" $(9, p .173)$. Este "querer" es de naturaleza racional y no una referencia a la mera emotividad, pues se puede querer cualquier cosa, pero que al surgir de la Razón, con arreglo a unas condiciones, ${ }^{12}$ posibilita el establecer juicios válidos para todos los seres que comparten esta categoría y que los convierte en agentes morales. Una norma así surgida sería entonces moralmente válida $\mathrm{Y}$ es obligatoria siempre, ya que las normas morales se expresan en forma de imperativos, que se pueden "entender como un deber que no es dependiente ni de los fines y preferencias subjetivos ni de la que para mí es meta absoluta de una vida buena, lograda o no fracasada" $(10, p .14)$.

\section{Lo ético y lo moral en el contexto plural de seres racionales: El contexto de la bioética}

Para Engelhardt el objetivo es lograr sentar las bases de una ética secular sin contenido porque no hay más opciones. Objetivo que prudencialmente puede ser compartido por todos los que vivimos en sociedades como las de

${ }^{12}$ Ya Engelhardt advertía que cuando se trata de razonar no todos razonan de la misma manera. Se pueden consultar otras obras de Habermas que explican más extensamente cuáles serían esas condiciones y reglas. hoy, pero que debe ser enunciado en otros términos. En esa vía la propuesta relacionada con la Teoría de la Acción Comunicativa de Habermas es para él un intento fallido de construir tal ética, por cuanto apela ya a un contenido: la $\operatorname{Razón}(1, p .60)$. Afirma que hoy sólo queda la posibilidad del acuerdo entre individuos expresado en el acuerdo de sus voluntades, lo que se llama consenso ${ }^{13}$, puesto que "la autoridad moral secular no es más ni es menos que la autoridad de quienes acuerdan colaborar"'(1, p.91). Aun así lamenta tal situación porque se perdió el contenido, pero deja sin explicar muy bien cómo se llegaría a tal acuerdo. En Engelhardt es la desilusión de no poder alcanzar lo imposible lo que lo lleva a plantear aquel objetivo. En nosotros es la ilusión de entendernos en otros términos. Es la necesidad de aceptar nuevas formas de comprender lo moral, dejando de lado la desesperación del "nunca jamás será como antes". Esto incluye pensar que es posible encontrar autoridad moral en un mundo postmetafísico que se ha dado cuenta de que en "realidad" vive en el mundo del lenguaje.

Al haber perdido el compartir un mismo contenido moral para todos no hemos dejado de estar obligados a tomar decisiones como colectivo, lo que nos obliga a buscar nuevas fuentes de legitimidad para esas decisiones. Y al aceptar que no todos razonan de la misma manera a la hora de las disputas morales, lo que se acepta es que no todos los usos de la Razón son válidos como fuente de autoridad moral. En esta perspectiva, el fantasma del relativismo moral hace su aparición en tanto no se haya hecho esta aclaración.

Por esto se ha propuesto una explicación del uso moral de la RPr, de tal modo que

\footnotetext{
${ }^{13}$ Es importante aclarar que desde la perspectiva moral, es decir, desde la perspectiva de la justicia, la meta del consenso incluye también la posibilidad del disenso razonable.
} 
no sea entendido como cualquier tipo de ejercicio de la Razón. Que esta confusión prevalezca en diferentes sectores de la sociedad no lleva a concluir que no haya allí una fuente de autoridad moral. Esta confusión es la expresión del desarreglo que hay entre una perspectiva aportada desde la Ontología (Metafísica) y la que es aportada desde la Política. Sólo desde esta última se comprende que el uso moral de la RPr es producto de una sociedad que promociona y posibilita en cada uno de sus miembros la adquisición de esta facultad en el proceso de desarrollo moral de cada uno de ellos. Estaríamos apuntando al último eslabón de una escala que midiera ese desarrollo, por ejemplo como en Kohlberg(11). El uso moral de la RPr se aprende, no se nace con él.

Se trata entonces de una tarea que rebasa la sola teoría moral. Y ya que la Bioética no es sólo teoría moral, cabe sugerir que, bajo la perspectiva que se ha venido señalando, ella también tendría una responsabilidad política, tanto en su propio seno como en la forma de plantear su responsabilidad social. El sentido de esta responsabilidad es el de trabajar para construir verdadera opinión pública, que es el espacio donde las sociedades de hoy ubican lo que todos quieren. Y que haya verdadera opinión pública significa que todos estén capacitados para colocar sus argumentos bajo un punto de vista moral, esto es, haciendo uso moral de la RPr. Lo que hay que hacer no es intentar construir una "ética general" sino un modelo de evaluación moral, un uso moral de la RPr, que permita un entendimiento mutuo y una evaluación de las diversas eticidades desde la perspectiva de la justicia.

Podrían señalarse concretamente dos cosas: primero, que sabemos que no se puede lograr hoy el sueño de un contenido compartido por todos, es decir, una Ética general. Segundo, que si lo sabemos es porque ya hemos dado un paso hacia lo que significa poder evaluar la situación tomando distancia de la pro- pia ética, esto es, de lo que ya podría implicar un punto de vista moral. Quien está ubicado en este punto puede obtener confianza en la evaluación moral en medio de la multiplicidad ética. Por otro lado, tal punto de vista contribuiría con mucho a lograr el acuerdo para convivir pacíficamente sin dar por perdida la autoridad moral ya que, manteniendo tal uso moral de la RPr, lograremos ver el deber moral como el deber de ser justos, esto es, entre otras cosas, el de respetar las múltiples visiones de la vida buena que están presentes, exigiendo de ellas una justificación cuando intenten ser implementadas en todo el escenario social. Pues, puede que la propia eticidad de algunos les indique buscar que todos los demás compartan la misma visión de lo bueno, lo cual es legítimo, y alcanzable, utilizando muchos mecanismos, excepto el de la fuerza. ${ }^{14}$

El reto es entonces promover, en este caso en y desde la Bioética, el hacer un uso moral, y no sólo ético o pragmático de la RP, cuando de decisiones públicas se trate. Una distinción así previene la inconsecuente actitud de tildar de malo todo aquello que no va con la propia Ética y en cambio permite adoptar una más tolerante y responsable. Esto se logra al entender que, si se pretende elevar una norma privada -el ethos- a norma general, es necesario argumentar y convencer sobre el por qué. Para esto todos tendrían que participar en la toma de decisiones sobre lo público, pues cada uno de los afectados tendrá mucho que decir sobre una norma que regirá su acción en la sociedad. Esto es, apelar al discurso como "forma de reflexión de la acción orientada hacia el entendimiento" $(12, p .51)$. No sólo como forma de decir qué es lo Bueno, en la vía de la fundamentación ética. $Y$ aunque esta vía se imbrica con la vía de fundamentación moral,

\footnotetext{
14“"Cuando se intente conseguir el permiso, consentimiento o acuerdo, lo único a lo que se deberá renunciar será a que quien busca el acuerdo utilice la fuerza coercitiva"( $1, p .95)$.
} 
pues es a partir de los mundos particulares -las eticidades- desde donde, inevitablemente, accedemos al discurso moral, no dejan de ser dos vías de fundamentación distinta.

A pesar de lo dicho, Engelhardt cree que es imposible construir a partir de la Razón puntos de vista moralmente normativos, es decir, aceptados por todos. Esta aseveración puede ser verdadera, pero sólo en cuanto se confunda el uso ético del uso moral de la RP en la construcción de la norma. Los juicios acerca de lo que es bueno tienen que ver con el "mundo de la vida", son condicionados cultural e históricamente, por ejemplo, un juicio desde determinada religión. Querer que todos compartan mi propia creencia está "bien", pero pensar que otros seres racionales estén obligados también a compartirla atenta contra la autonomía, lo que sería "injusto" hoy. Además, no parece factible que una persona pueda desear, libre y racionalmente, que cualquier otra distinta de sí misma venga a imponerle por la fuerza una creencia distinta de la propia. Esta acción se evidenciaría inmoral al intentar universalizar la norma que la rige, esto es, utilizando el imperativo categórico. Nadie que haya aprendido a hacer un uso moral de la RPr optaría por obligar a otros a compartir la misma creencia.

Puede pensarse que sí es posible construir puntos de vista moralmente normativos para todos, ya que ningún ser racional puede optar por no hacer lo que "debe" si está haciendo uso moral de la RPr y a la vez sentirse "bien", pues los sentimientos morales siempre están presentes en el obrar de las personas. Que esto no ocurra tal cual en el "mundo de la vida" significa que se ha retrocedido tan sólo al uso ético y, muchas veces, lamentablemente, al mero uso pragmático ${ }^{15}$, de la RPr.

\footnotetext{
${ }^{15}$ Quien está ubicado en un punto de vista moral comparte con Kant la apreciación de que a las demás personas no se les puede ver exclusivamente como un medio -instrumental o estratégicamente-, sino también como un fin en sí mismos.
}

Se ha dicho que utilizar el punto de vista moral significa llevar a cabo juicios de imparcialidad. Para llevarlos a cabo no queda otro camino que el ejercicio conceptual de la universalización, que significa implicar a todos, y sólo a todos, los seres racionales, no en tanto los únicos objetos de la norma sino en tanto legisladores. Esto se logra nuevamente a través del imperativo categórico, que representa "una acción como objetivamente necesaria por sí misma, sin referencia a otro fin"(9, p.159). Y en tanto "los imperativos sean solamente fórmulas para expresar la relación de leyes objetivas del querer en general con la imperfección subjetiva de la voluntad de este o aquel ser racional"( 9, p.159), los juicios morales son por definición abstractos y universales, y la única posibilidad de que hagan parte del mundo de la vida es en la aplicación como evaluación desde el punto de vista de la justicia de las múltiples eticidades, tomando cierta distancia cuando se trata de la propia.

No se trata de más, pues "lo más que puede pretender una 'teoría moral'es ilustrar a los agentes morales acerca de lo que en condiciones modernas nadie ignora"(12, p.41). 


\section{Referencias}

1. Engelhardt T. Los fundamentos de la bioética. $1^{\text {a }}$ ed. Barcelona: Paidos; 1995.

2. Lyotard J. La condición postmoderna. 5ª ed. Madrid: Cátedra; 1994.

3. MacIntyre A. Tras la virtud. Barcelona: Crítica; 2001.

4. Camps V. et. al. Concepciones de la Ética. Madrid: Trotta; 1992.

5. Wittgenstein L. Conferencia sobre ética: con dos comentarios sobre la teoría del valor. $2^{\mathrm{a}}$. ed. Barcelona: Paidos; 1990.

6. Tugendhadt E. Diálogo en Leticia. Barcelona: Gedisa; 2000.

7. Taylor Ch. Sources of the self. Cambridge, MA: Harvard University Press; 1989.

8. MacIntyre A. Tres versiones rivales de la ética: enciclopedia, genealogía y tradición. Madrid: Rialp; 1992.

9. Kant I. Fundamentación de la metafísica de las costumbres. Edición Bilingüe. Barcelona: Ariel; 1996.

10. Habermas J. Acerca del Uso Ético, Pragmático y Moral de la Razón Práctica. Filosofía. Revista del postgrado de Filosofía de la Universidad de Los Andes. Mérida 1990; 1.

11. Kohlberg L. Psicología del desarrollo moral. Bilbao: Desclee de Brouwer; 1992.

12. Jiménez RM. Introducción. En: Habermas J. Escritos sobre moralidad y eticidad. Barcelona: Paidos; 1991. 